\title{
ALTERNATE MATERIAL FOR ELEVATED TEMPERATURE TURBINE COOLING PLATE APPLICATIONS
}

\author{
Jon R. Groh ${ }^{1}$, David P. Mourer ${ }^{2}$ \\ ${ }^{1}$ GE Aircraft Engines, 1 Neumann Way, Evendale, Ohio \\ ${ }^{2}$ GE Aircraft Engines, Lynn, Mass
}

\begin{abstract}
Keywords: René104, As-HIP, René95, powder, rotor cooling plate, tensile, dwell fatigue, sustained-peak LCF, simulated mission fatigue, thermal exposure, metallurgical stability, microstructure, hardness
\end{abstract}

\begin{abstract}
Extrude + isoforged Ni-base powder alloy René104 was initially developed for critical rotating applications subject to elevated temperature for extended periods. The excellent dwell fatigue behavior and metallurgical stability makes this a viable candidate for material upgrade to improve the durability of non-critical turbine engine components that encounter severe operating conditions. This program was performed to address distress and metallurgical changes observed after field service of rotor cooling plates in aircraft turbine engines. Temperature capability is a key factor affecting hardware durability as commercial engine design temperatures and take-off cycle severity continues to climb.
\end{abstract}

Full-scale forgings were processed for manufacture of finished parts for engine test and destructive evaluation to determine behavior for conditions specific to rotor cooling plates. Material behavior in the $700-870^{\circ} \mathrm{C}$ range was emphasized. The advantages of René104 were quantified relative to the current As-HIP René95 product using fatigue cycling with a super-imposed dwell at maximum load, simulated mission fatigue cycling, and tensile test of specimens after stressed pre-exposure. Dwell fatigue capability was improved by $\sim 110^{\circ} \mathrm{C}$ with a nominal life advantage ranging from 10-100X, increasing with test temperature. Fatigue life advantage was nominally $4 \mathrm{X}$ when continuously cycled to simulate mission profiles.

A series of oversize creep-rupture tests were performed to provide material for tensile test following a stressed thermal exposure at $760-815^{\circ} \mathrm{C}$. Significant degradation of room temperature and $650^{\circ} \mathrm{C}$ tensile behavior due to pre-exposure was not encountered, although microstructural changes were observed. Metallurgical stability by this measure was clearly superior to that of As-HIP René95. Changes in René104 microstructural features and hardness with time at temperature are also presented.

\section{Introduction}

Turbine engine cooling plates and blade retainers are frequently subjected to an extreme thermal environment that contributes to non-catastrophic distress (Figure 1) discovered upon engine teardown. Analyses of field-returned hardware provide evidence of fracture via dwell-related fatigue, a performance metric also of growing criticality for disk, shaft, and seal components. Microstructural features of field returned hardware provide evidence of thermal excursions approaching $870^{\circ} \mathrm{C}$. Upgrade to an alloy with greater thermal capability was considered an opportunity to improve turbine component durability and increase rotor maintenance intervals.
As a result of uncertainties regarding this dynamic environment, a matrix of conventional and mission simulation testing was required to quantify the performance benefit to substantiate engine test of finished hardware. Alloy René104, an extrude+ isoforged Ni-base powder alloy partially developed under NASA-Enabling Propulsion Materials programs ${ }^{(1,2)}$ was considered for a drop-in performance improvement versus fine grain As-HIP René95 (3). Nominal compositions are provided for reference.

Table I

Alloy Composition in Weight \%, Balance Ni

\begin{tabular}{|c|c|c|c|c|c|c|c|c|c|}
\hline \begin{tabular}{|l} 
Alloy Wt\% \\
\end{tabular} & Co & $\mathrm{Cr}$ & Mo & $\mathbf{W}$ & $\mathrm{Nb}$ & Al & $\mathbf{T i}$ & Ta & $\mathbf{C}$ \\
\hline${\text { Rene' } 104^{(4)}}^{(4)}$ & $\begin{array}{l}14- \\
23\end{array}$ & $\begin{array}{l}11- \\
15\end{array}$ & $\begin{array}{l}2.7- \\
5\end{array}$ & $\begin{array}{l}0.5- \\
3\end{array}$ & $\begin{array}{l}0.25 \\
-3\end{array}$ & $2-5$ & $3-6$ & $\begin{array}{l}0.5- \\
4\end{array}$ & $\begin{array}{l}0.015 \\
0.1\end{array}$ \\
\hline \begin{tabular}{|l|} 
As-HIP \\
Rene'95 $^{(5)}$
\end{tabular} & 8 & 13 & 3.5 & 3.5 & 3.5 & 3.5 & 2.5 & na & 0.06 \\
\hline \begin{tabular}{|l} 
Rene'$^{\prime} 88 \mathrm{DT}$ \\
\end{tabular} & 13 & 16 & 4 & 4 & 0.7 & 2.2 & 3.8 & na & 0.05 \\
\hline
\end{tabular}

Improved metallurgical stability is desired to ensure mechanical capability during service under severe thermal and stress conditions. Microstructural stability is expected to benefit the dwell fatigue resistance of the alloy system. Quantification of mechanical property retention against proven alloy systems is necessary to abate risk of embrittlement encountered on earlier Nibase alloy systems.

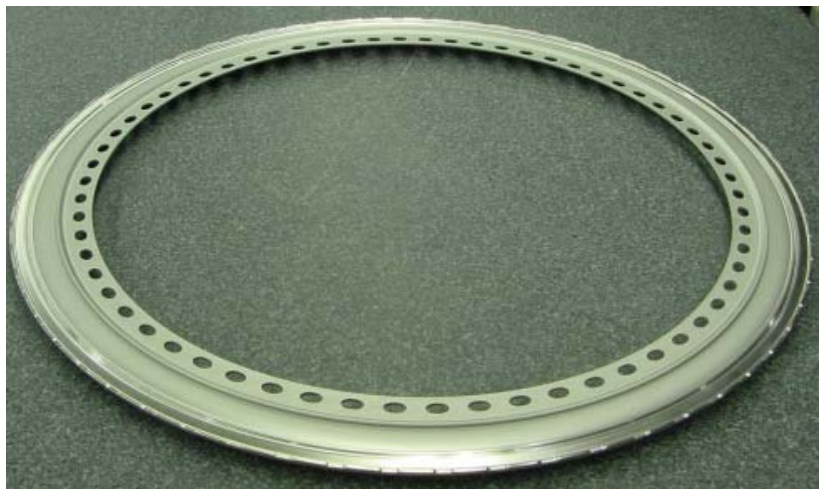

Figure 1 Finished René104 cooling plate representing non-critical rotor components that show distress related to extreme thermal conditions. Nominal outer diameter is $50 \mathrm{~cm}$. 


\section{Experimental Procedure}

$\underline{\text { Materials }}$

Powder metal René104 isothermal forgings were processed from billet similar to the René88DT methods described in reference 6, with the exception of size and a moderate cooling rate from supersolvus solution heat treat. Following quench, forgings were subjected to an intermediate stabilization and final age cycle to a schedule similar to that of Waspaloy ${ }^{(7,8)}$. Finished components were nominally $55 \mathrm{~cm}$ in diameter with an ID of $35 \mathrm{~cm}$ and $6 \mathrm{~cm}$ thick. As-HIP René95 specimens were excised from production cooling plate stock of similar dimension, but solutioned below the $\gamma^{\prime}$-solvus temperature, quenched and aged ${ }^{(5)}$.

\section{$\underline{\text { Test Methods }}$}

Sustained-peak LCF (SPLCF) behavior was determined for proposed René104 and current As-HIP René95 alloys. Notched specimens (Kt 2.7) were cycled in load-control using a trapezoidal waveform with 90-second dwell at maximum load (Figure 2A). Data were compared to average LCF behavior developed with a triangular waveform at $20 \mathrm{cpm}$ (Figure $2 \mathrm{~B}$ ).

Simulated mission fatigue (SMF) tests were performed to quantify impact of a material upgrade on the life limiting location. A simplified fatigue test was derived to represent the complexity of an engine mission. Notched specimens (Kt 1.8) were performed in load control with an induction coil programmed to vary temperature out-of-phase with stress (Figure 2C). No intentional dwell period was imposed as in isothermal SPLCF testing described above. The initial SMF test condition ranged from $427^{\circ} \mathrm{C}, 20 \mathrm{MPa}$ tensile to $760^{\circ} \mathrm{C}, 14.5 \mathrm{MPa}$ compressive stress. Thermal ramp was in excess of $650^{\circ} \mathrm{C} /$ minute during the temperature increase, and slightly over $300^{\circ} \mathrm{C} /$ minute during the cool to $427^{\circ} \mathrm{C}$ with linear ramps. A second series of SMF testing ranged from 427 to $815^{\circ} \mathrm{C}$, also out-of phase, to reflect a more severe hot gas ingestion event.

Metallurgical stability was measured by tensile and hardness retention after extended exposure to high temperature. As initially described in reference 9, threaded ends of over-size René 104 creep bars were used as input stock for tensile test bar manufacture following completion of creep tests at $760-815^{\circ} \mathrm{C}$ for various times. Upon creep-rupture test completion, tensile specimens were manufactured from either end of the geometry indicated in Figure 3. Specimens removed from the ' $A$ ' end were subsequently tested at room temperature, the ' $\mathrm{B}$ ' end was tested at $650^{\circ} \mathrm{C}$. Results were compared to unexposed data from the same forging for evidence of overage or embrittlement by this measure. René104 tensile property retention was also compared to that of As-HIP René95 following an unstressed pre-exposure. Macrohardness, HRc, was determined on the shoulder of bars prior to room temperature test. One creep $870^{\circ} \mathrm{C}$ creep specimen was also hardness tested and evaluated metallographically; no tensile data were generated for this condition.

\section{$\underline{\text { Microscopy }}$}

Optical and field emission scanning electron microscopy techniques were performed on the as-manufactured and preexposed René104 conditions to determine microstructural evolution to mechanical behavior. Test gages of the over-size René 104 creep specimens were prepared mechanically on a plane normal to the applied stress axis, and immersion etched to reveal grain structure. Following removal from the mount media, each was re-prepared electrolytically in a solution of $300 \mathrm{ml}$ ethylene glycol+80ml Perchloric $+500 \mathrm{ml}$ Methanol. The following parameters were applied in the presence of a platinum cathode. Nominal specimen area was $3 . \mathrm{cm}^{2}$. Preparation and optical microscopy were performed by GEAE, field emission SEM was provided by The Ohio State University.

\begin{tabular}{lcc} 
& Voltage & Time \\
\cline { 2 - 3 } Electropolish & 28 & 15 seconds \\
Electro-etch & 5 & $3-6$ seconds
\end{tabular}

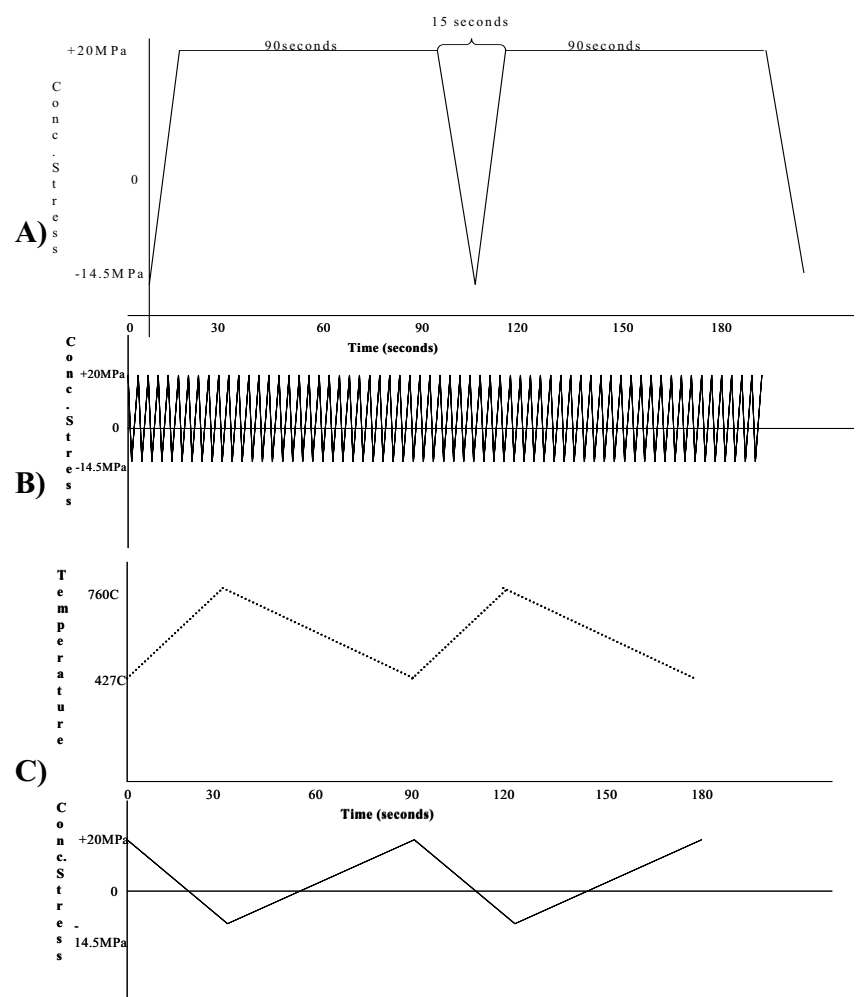

Figure 2 Fatigue cycle profiles performed for A) Sustainedpeak LCF, B) continuous cycle $L C F$ and $C$ ) simulated mission fatigue. The latter mission was also performed to a maximum temperature of $815^{\circ} \mathrm{C}$.

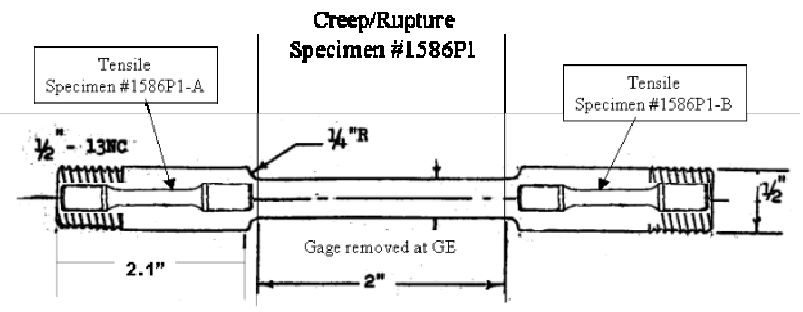

Figure 3 Oversize creep specimen used to evaluate the metallurgical stability of René104. Sub-size tensile bars were excised from either end. Gage section was subjected to microstructural evaluation. 


\section{Results and Discussion}

Microstructure of as-heat treated René104 evaluated in this study are presented in Figure 4. Average grain size throughout the crosssection ranged from ASTM 6 to 7.5. The As-HIP René95 product measured an average ASTM 11.5.

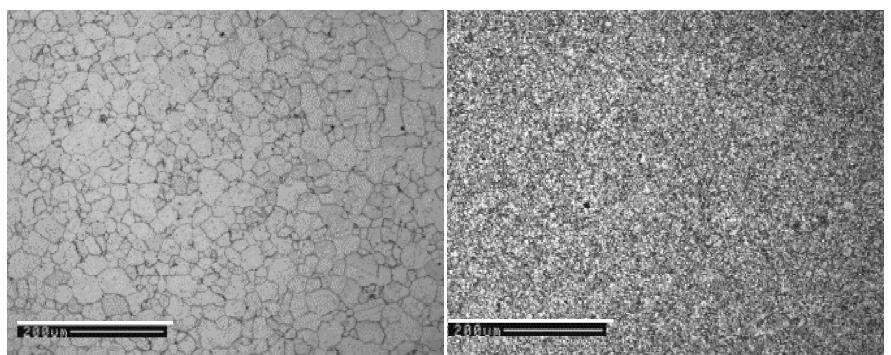

Figure 4 Equiax grain structure of A) René104 and B) AsHIP René95 representing material condition prior to thermal exposure.

\section{$\underline{\text { Dwell Fatigue }}$}

Sustained-peak LCF results are provided in Table II and Figures $5 \mathrm{~A}$ through $5 \mathrm{C}$, relative to the continuous cycling LCF behavior of each alloy. These figures illustrate the life debit encountered with a dwell at maximum load when cycled at elevated temperatures. Isothermal comparisons indicate René104 has a nominal 10x life benefit at $704^{\circ} \mathrm{C}, 100 \mathrm{x}$ at 760 and $815^{\circ} \mathrm{C}$ when cycled under these dwell conditions (Figure 6). For a given stress range, The René 104 forging showed a nominal $110^{\circ} \mathrm{C}$ benefit over the As-HIP René95 behavior.

Table II

Sustained-peak LCF

Kt 2.63, R=0, 90-second dwell at max, Load-control

\begin{tabular}{|c|c|c|c|c|c|c|}
\hline Alloy & Temp C & $\begin{array}{c}\text { Max Conc. } \\
\mathrm{MPa}\end{array}$ & $\begin{array}{c}\text { Measured } \\
\text { notch radius, } \\
\mathrm{mm}\end{array}$ & $\begin{array}{c}\mathrm{Max} \mathrm{Net}_{\mathrm{MPa}} \\
.\end{array}$ & Failure Cycles & $\begin{array}{l}\text { Conc. PsAlt } \\
\text { Mpa }\end{array}$ \\
\hline Rene104 & 704 & 24.4 & 0.35 & 9.3 & 12,936 & 11.6 \\
\hline Rene104 & 704 & 24.4 & 0.32 & 9.3 & 19,278 & 11.6 \\
\hline Rene104 & 704 & 24.4 & 0.35 & 9.3 & 23,684 & 11.6 \\
\hline Rene104 & 704 & 29.0 & 0.35 & 11.0 & 4,435 & 13.8 \\
\hline Rene104 & 704 & 29.0 & 0.33 & 11.0 & 3,390 & 13.8 \\
\hline Rene104 & 704 & 29.0 & 0.35 & 11.0 & 5,601 & 13.8 \\
\hline Rene104 & 760 & 24.4 & 0.34 & 9.3 & 48,422 & 11.6 \\
\hline Rene104 & 760 & 24.4 & 0.35 & 9.3 & 48,056 & 11.6 \\
\hline Rene104 & 760 & 24.4 & 0.35 & 9.3 & 11,390 & 11.6 \\
\hline Rene104 & 760 & 29.0 & 0.36 & 11.0 & 791 & 13.8 \\
\hline Rene104 & 760 & 29.0 & 0.35 & 11.0 & 2,030 & 13.8 \\
\hline Rene104 & 760 & 29.0 & 0.35 & 11.0 & 23,343 & 13.8 \\
\hline Rene104 & 816 & 18.3 & 0.35 & 7.0 & 8,113 & 8.7 \\
\hline Rene104 & 816 & 21.4 & 3.48 & 8.1 & 2,634 & 10.1 \\
\hline Rene104 & 816 & 21.4 & 0.34 & 8.1 & 1,162 & 10.1 \\
\hline $\begin{array}{l}\text { Rene104 } \\
\end{array}$ & 816 & 21.4 & 3.40 & 8.1 & 1,351 & 10.1 \\
\hline Rene104 & 816 & 24.4 & 0.36 & 9.3 & 4,996 & 11.6 \\
\hline Rene104 & 816 & 24.4 & 0.35 & 9.3 & 3,726 & 11.6 \\
\hline Rene104 & 816 & 29.0 & 0.36 & 11.0 & 937 & 13.8 \\
\hline $\begin{array}{l}\text { Rene104 } \\
\end{array}$ & 816 & 29.0 & 0.35 & 11.0 & 675 & 13.8 \\
\hline Rene104 & 871 & 18.3 & 0.37 & 7.0 & 1,814 & 8.7 \\
\hline $\begin{array}{l}\text { Rene104 } \\
\end{array}$ & 871 & 18.3 & 0.34 & 7.0 & 2,183 & 8.7 \\
\hline Rene104 & 871 & 24.4 & 0.35 & 9.3 & 235 & 11.6 \\
\hline Rene104 & 871 & 24.4 & 0.34 & 9.3 & 341 & 11.6 \\
\hline AS-HIP R95 & 704 & 18.3 & 0.34 & 7.0 & 10,479 & 8.7 \\
\hline AS-HIP R95 & 704 & 24.4 & 0.34 & 9.3 & 1,963 & 11.6 \\
\hline AS-HIP R95 & 704 & 24.4 & 0.33 & 9.3 & 3,697 & 11.6 \\
\hline AS-HIP R95 & 704 & 29.0 & 0.35 & 11.0 & 1,466 & 13.8 \\
\hline AS-HIP R95 & 704 & 29.0 & 0.33 & 11.0 & 293 & 13.8 \\
\hline AS-HIP R95 & 760 & 18.3 & 0.34 & 7.0 & 1,836 & 8.7 \\
\hline AS-HIP R95 & 760 & 24.4 & 0.34 & 9.3 & 348 & 11.6 \\
\hline AS-HIP R95 & 760 & 24.4 & 0.34 & 9.3 & 138 & 11.6 \\
\hline AS-HIP R95 & 816 & 24.4 & 0.34 & 9.3 & 26 & 11.6 \\
\hline
\end{tabular}

A)
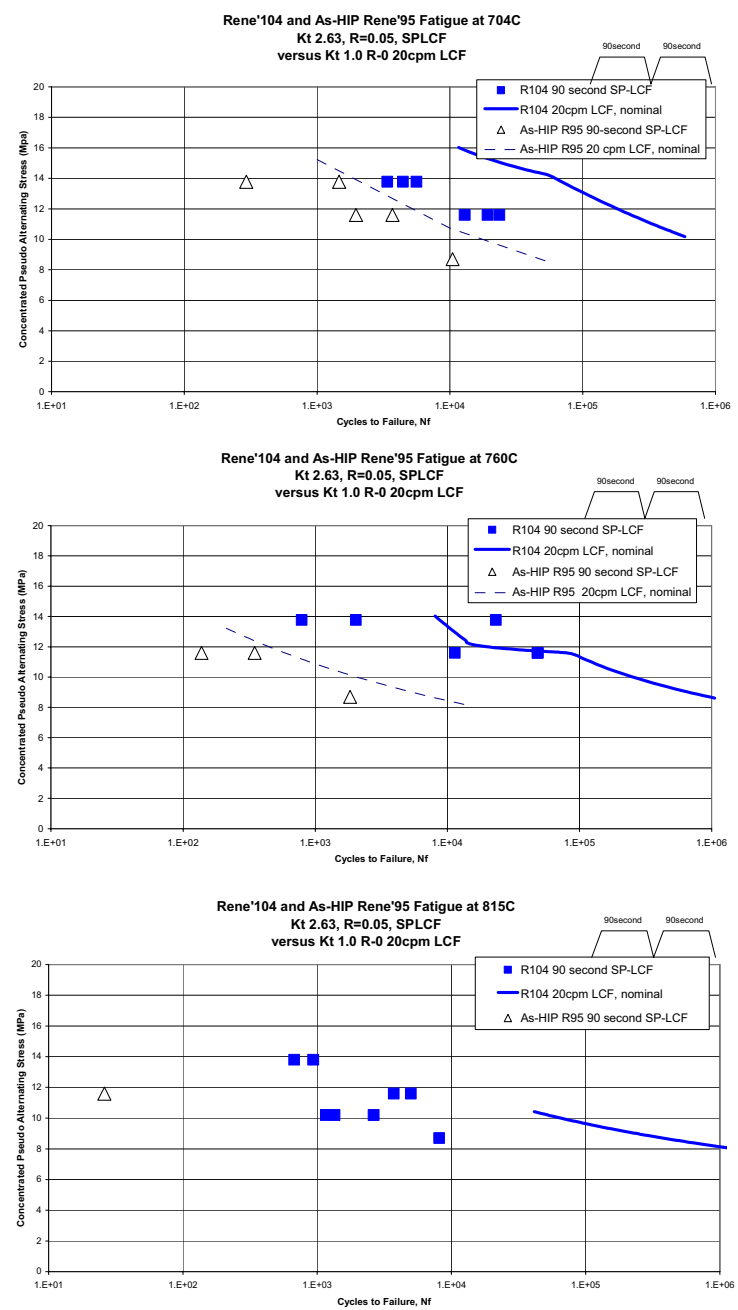

C)

Figure 5 SPLCF data versus continuous-cycled LCF behavior. René104 shows a nominal 10X benefit at $704^{\circ} \mathrm{C}$ and $100 \mathrm{X}$ at 760 and $815^{\circ} \mathrm{C}$ versus AsHIP René95.

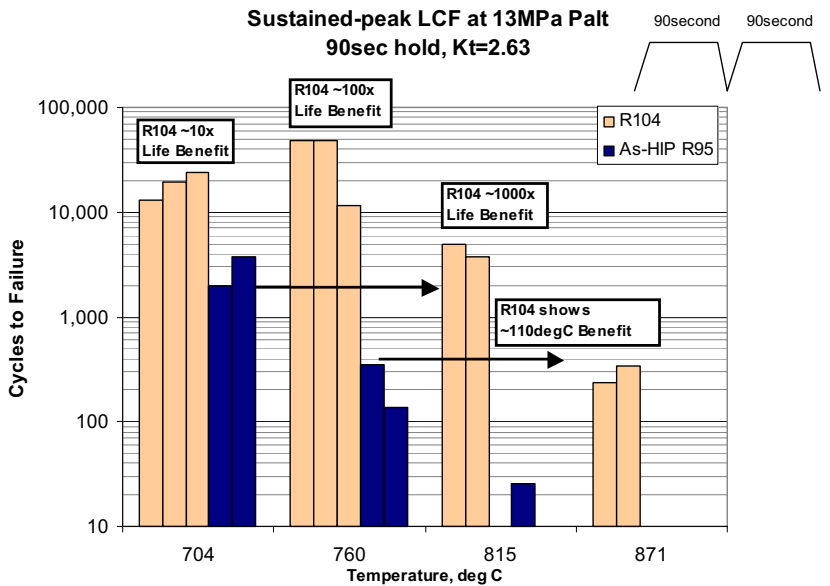

Figure 6 Behavior at this pseudostress condition shows a nominal $110^{\circ} \mathrm{C}$ advantage in capability over AsHIP René95. 


\section{$\underline{\text { Simulated Mission Fatigue }}$}

Simulated mission test cycles to failure for each alloy and condition are listed in Table III and presented in Figure 7. The René 104 advantage in cycles to failure to this profile was $3.1 \mathrm{X}$ and 4.7X that measured for As-HIP René95 for $427-760^{\circ} \mathrm{C}$ and $427-815^{\circ} \mathrm{C}^{\circ} \mathrm{F}$ mission cycles, respectively. Data were instrumental in substantiating René104 hardware for factory and field engine tests.

Table III

Simulated Mission Fatigue

\begin{tabular}{|l|c|l|c|}
\hline \multicolumn{1}{|c|}{ ID } & ALLOY & \multicolumn{1}{|c|}{ MISSION } & Nf \\
\hline $1586-S 35$ & R104 & $\begin{array}{l}760 \text { to } 427 C \\
-14.5 \text { to }+20 \mathrm{MPa}\end{array}$ & 6335 \\
\hline $1582-S 9$ & $\mathrm{R} 104$ & $\begin{array}{l}760 \text { to } 427 \mathrm{C} \\
-14.5 \text { to }+20 \mathrm{MPa}\end{array}$ & 4430 \\
\hline $1586-S 25$ & $\mathrm{R} 104$ & $\begin{array}{l}760 \text { to } 427 \mathrm{C} \\
-14.5 \text { to }+20 \mathrm{MPa}\end{array}$ & 5618 \\
\hline R95-SMF1 & As-HIP R95 & $\begin{array}{l}760 \text { to } 427 \mathrm{C} \\
-14.5 \text { to }+20 \mathrm{MPa}\end{array}$ & 1951 \\
\hline R95-SMF3 & As-HIP R95 & $\begin{array}{l}760 \text { to } 427 \mathrm{C} \\
-14.5 \text { to }+20 \mathrm{MPa}\end{array}$ & 1548 \\
\hline & $\mathrm{R} 104$ & $\begin{array}{l}815 \text { to } 427 \mathrm{C} \\
-14.5 \text { to }+20 \mathrm{MPa}\end{array}$ & 3456 \\
\hline 1582-S13 & R104 & $\begin{array}{l}815 \text { to } 427 \mathrm{C} \\
-14.5 \text { to }+20 \mathrm{MPa}\end{array}$ & 3317 \\
\hline 1586-S28 & As-HIP R95 & $\begin{array}{l}815 \text { to } 427 \mathrm{C} \\
-14.5 \text { to }+20 \mathrm{MPa}\end{array}$ & $\mathbf{7 9 3}$ \\
\hline R95-SMF4 & As-HIP R95 & $\begin{array}{l}815 \text { to } 427 \mathrm{C} \\
-14.5 \text { to }+20 \mathrm{MPa}\end{array}$ & 642 \\
\hline R95-SMF5 & & & \\
\hline
\end{tabular}

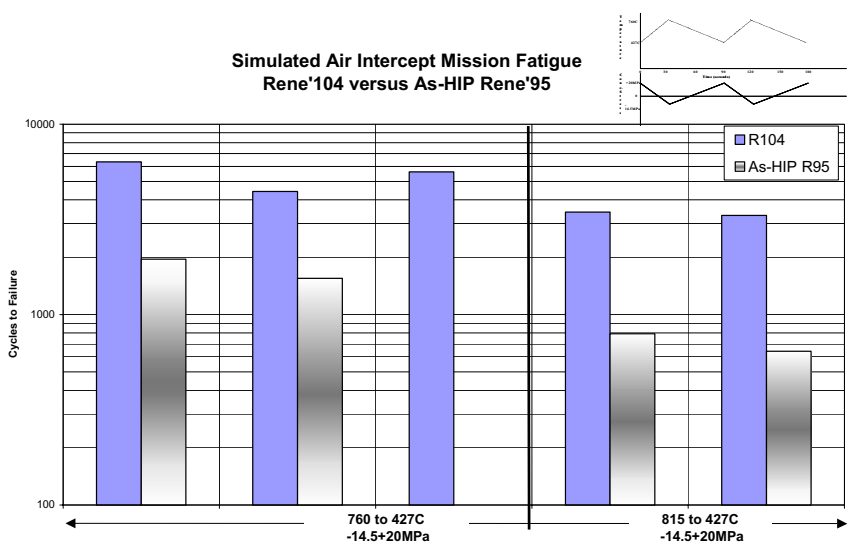

Figure 7 Mission simulation data for the profile represented by Figure 2C) indicate a René104 life advantage of 3.1X that of As-HIP René95 when cycled out-ofphase with stress between 427 and $760^{\circ} \mathrm{C}$, and 4.7X cycling from 427 and $815^{\circ} \mathrm{C}$.

\section{Metallurgical Stability}

Tensile properties of each alloy in the as-heat treated and thermal pre-exposure conditions are provided in Table IV and Figure 8. The $650^{\circ} \mathrm{C}$ tensile behavior after 25 hours at 760 and $815^{\circ} \mathrm{C}$ showed little impact on Rene' while As-HIP Rene'95 exhibits an 8$15 \%$ loss of strengths and $18-37 \%$ lower ductility.
Table IV

25-hour Exposure on $650^{\circ} \mathrm{C}$ Tensile Retention

\begin{tabular}{|c|c|c|c|c|}
\hline $\begin{array}{c}\text { Normalized } \\
\text { Behavior }\end{array}$ & $\begin{array}{c}\text { R104 760C, } \\
\text { 25 Hrs }\end{array}$ & $\begin{array}{c}\text { R104 815C, } \\
\text { 25 Hrs }\end{array}$ & $\begin{array}{c}\text { R95 760C, } \\
\text { 25 Hrs }\end{array}$ & $\begin{array}{c}\text { R95 815C, } \\
\text { 25 Hrs }\end{array}$ \\
\hline Ultimate Strength & 0.98 & 0.98 & 0.92 & 0.94 \\
\hline $0.2 \%$ Yield & 1.02 & 0.98 & 0.87 & 0.90 \\
\hline \%Elongation & 0.99 & 1.07 & 0.65 & 0.63 \\
\hline \%Red of Area & 0.98 & 0.97 & 0.82 & 0.66 \\
\hline
\end{tabular}

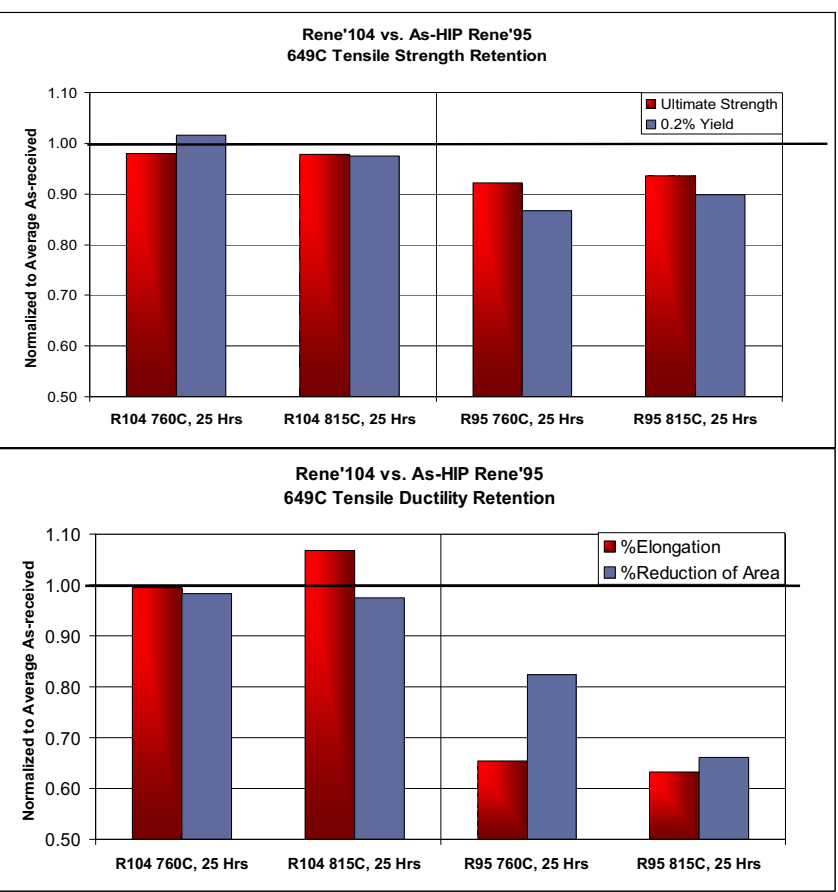

Figure 8 Influence of thermal pre-exposure on retention of René104 and As-HIP René95 tensile properties following 25-hour pre-exposures. René 104 exposures were performed with minor stress.

Additional tensile data versus thermal exposure are presented as a function of Larson Miller parameter:

$$
\operatorname{LMP}(1000)=\left(\mathrm{T}^{\circ} \mathrm{F}+460\right)(25+\log (\mathrm{t}, \mathrm{Hrs}))
$$

As-heat treated properties are arbitrarily assigned an LMP of 41,500 for plotting purposes. Data include the conditions of Table IV and extend to $870^{\circ} \mathrm{C}, 430$ hours. Curve fits are provided only to show general trends, assignment of the initial LMP affects any derived model.

Room temperature tensile response showed stability throughout the temperature and times evaluated (Figure 9). Similar results were obtained from a cooperative GE Global Research program to evaluate René104 exposed to 732 and $738^{\circ} \mathrm{C}$ exposures through 1,000 hours ${ }^{(10)}$. These data confirmed that stress during thermal exposure does not affect over-age by this measure. This conclusion can also be reached for alloy 718 by comparing data presented in references 9 and 11. Room temperature behavior of René104 was nearly constant through the evaluated range of thermal exposures. 
At the relatively sensitive $650^{\circ} \mathrm{C}$ tensile condition, the onset of strength decay was significantly delayed relative to that recorded in an earlier study of As-HIP René95 following unstressed thermal exposure $^{(12)}$. The tensile strength advantage of the fine grain AsHIP René95 is nearly eliminated following thermal exposure (Figure 10, LMP 49,000). René104 tests showed loss of strength only after exceeding an LMP value of approximately 53,000 and clearly superior to that of the As-HIP René95 product. Similar to room temperature results, René104 ductility response showed no pre-exposure effect; indicating that René 104 does not, within the limits of processing and composition evaluated, suffer any evidence of gross embrittlement.

A similar Larson Miller profile of average hardness presents asheat treated and thermal exposed conditions (Figure 11). Hardness increased slightly prior to overage. An increase of $2 \mathrm{HRc}$ is followed by decay to below the initial value at LMP beyond 56,000 . Hardness response is not considered a sensitive indicator of age condition in $\gamma$-strengthened Ni-base Superalloys. Readings below HRc 40 would indicate a severely over-aged condition.
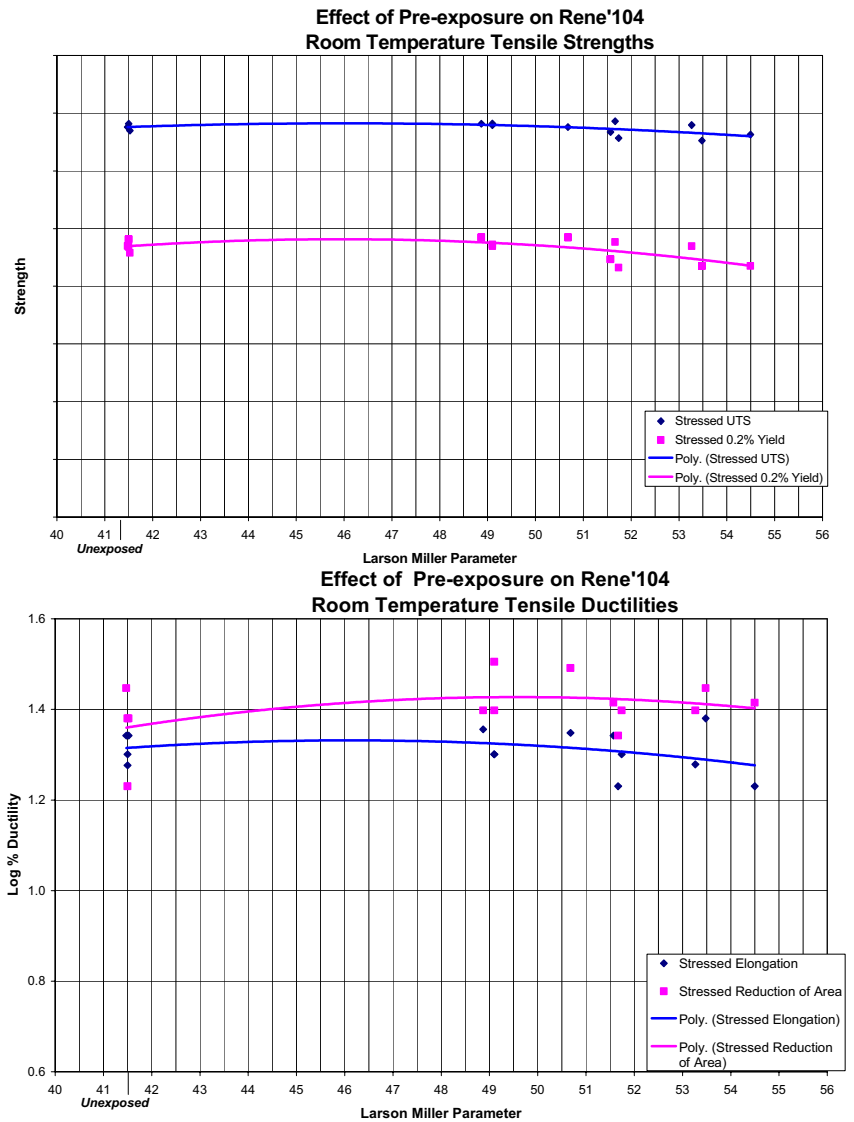

Figure 9 Influence of thermal pre-exposure on room temperature tensile retention of René104. Tensile behavior is not affected by these conditions.

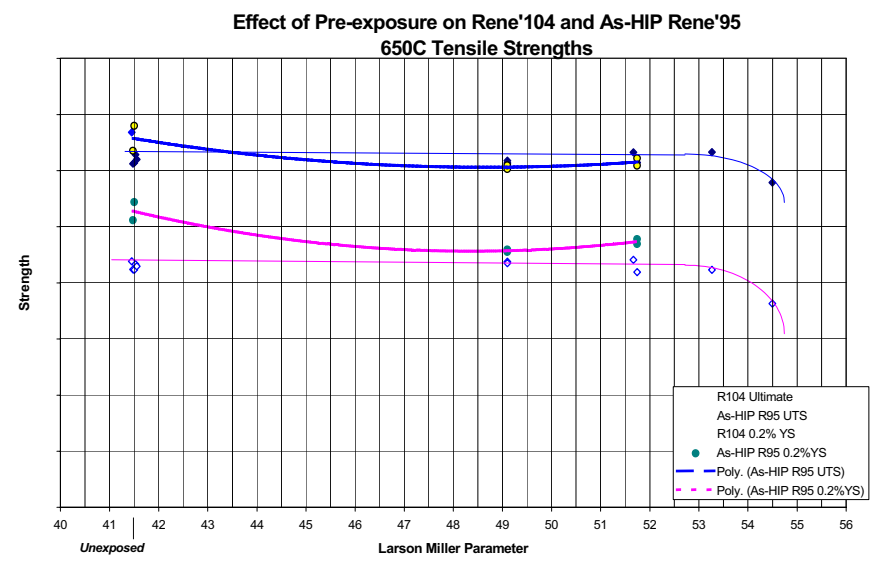

Effect of Pre-exposure on Rene'104 and As-HIP Rene'95

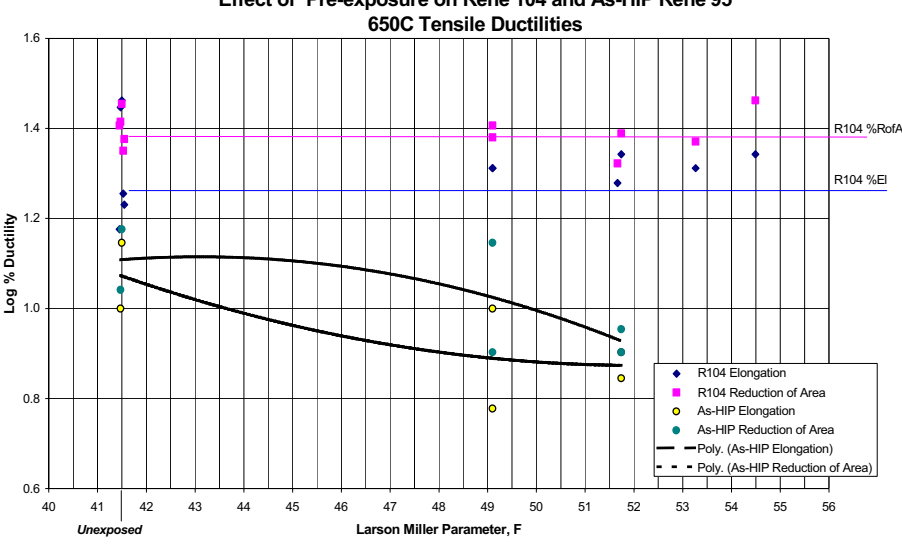

Figure 10 Influence of thermal pre-exposure on René104 tensile retention shows improved stability versus As-HIP René95 when tested at $650^{\circ} \mathrm{C}$.

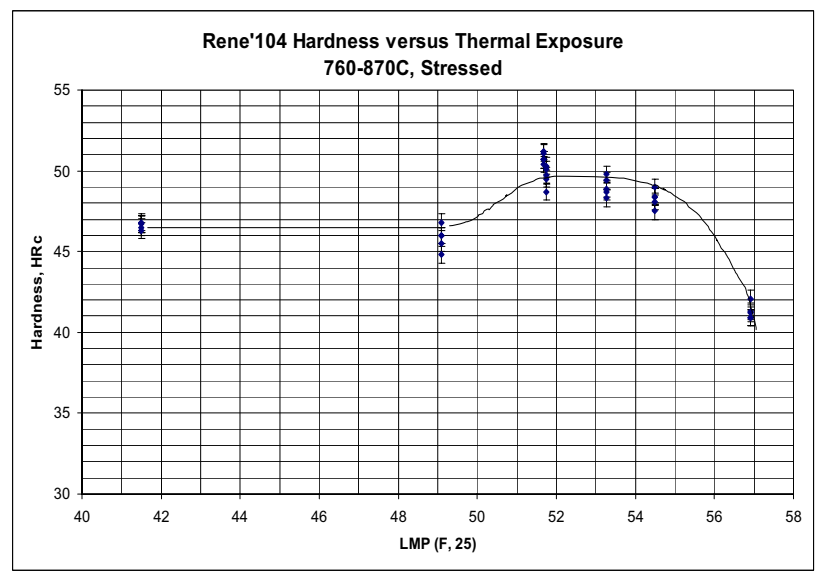

Figure 11 René104 hardness representing as-heat treated and stressed thermal pre-exposure conditions. 


\section{Microstructural Stability}

The electron images representing René104 microstructure without pre-exposure show a duplex $\gamma^{\prime}$ size distribution consisting of secondary precipitation $(\sim 0.35 \mu \mathrm{m})$ during quench from supersolvus solution, plus a tertiary precipitate $(<0.09 \mu \mathrm{m})$ formed and/or coarsened during subsequent stabilization and aging cycles (Figure 12). Primary $\gamma$ associated with fine grain processing is absent due to solutioning above the solvus temperature to enable grain growth to a more damage tolerant grain structure similar to that of René88DT ${ }^{(13,14)}$. Intragranular borides and primary carbides are also present in these micrographs and stable throughout the evaluated range of temperature-time. Secondary carbides are not evident in these images, but extraction work was not performed.

Quench models show the specimen pre-exposed to $760^{\circ} \mathrm{C} / 25$ hour was cooled with an average cooling rate of $\sim 20^{\circ} \mathrm{C} /$ minute $^{(7)}$. Although a nearly identical rate to the as-heat treated condition, Figure 13 presents a dendritic cooling $\gamma^{\prime}$ measuring $\sim 0.45 \mu \mathrm{m}$., evidence of slow cool through the $\gamma$-solvus. Prior René 104 cooling rate studies show this morphology precipitates at singleslope average cooling rates of $<15^{\circ} \mathrm{C} /$ minute or "2-slope quench" associated with locations internal to the heat-treated shape ${ }^{(15)}$. Tensile response was not reduced by this microstructure. Coarsening of the fine $\gamma$ precipitate is implied in these micrographs. Common to As-HIP René95, secondary carbides are observed at the imaged grain boundary for this pre-exposure. Grain boundary precipitates were assumed $\mathrm{Cr}$-rich $\mathrm{M}_{23} \mathrm{C}_{6}$ and borides, as reported for René88DT exposed at $732^{\circ} \mathrm{C}$ for 10,000 hours (LMP $52,500, \mathrm{~F}, 25$, ref. 14).

The balance of pre-exposed René104 Cooling Plate specimens were modeled to a similar average cooling rate and reflect the quench rate and path reflected by the baseline condition (Figures 14-17 versus Figure 12). Progressive growth and coalescence of cooling $\gamma^{\prime}$ occurs in situ with dissolution of the fine $\gamma^{\prime}$ precipitates. Aging $\gamma^{\prime}$ is dissolved between 150 and 636 hours at $815^{\circ} \mathrm{C}$ and is not present in the $870^{\circ} \mathrm{C} / 430$ hour condition. The latter condition shows evidence coalescence of cooling $\gamma^{\prime}$, particularly along grain boundaries (Figure 17).

A semi-continuous, secondary precipitate was present at grain boundaries after $760^{\circ} \mathrm{C} / 599$ hours. This phase remains discontinuous after 636 hours at $815^{\circ} \mathrm{C}$. A continuous grain boundary film and was present after 430 hours of creep at $870^{\circ} \mathrm{C}$ (Figure 17); no tensile response was generated for this condition.

No evidence of acicular, topologically close-packed phases, reported previously for select Ni-base alloys ${ }^{(12-13,}$ 16-17), was observed in the current study. Improved metallurgical stability likely provides a significant contribution to the superior dwell fatigue (sustained-peak LCF) behavior demonstrated for this alloy.

\section{Summary}

The high temperature behavior and metallurgical stability of René104 were developed for conditions and applications beyond the original intent for this alloy system. The advantages over AsHIP René95 were quantified for the targeted cooling plate application. The benefit relative to the fine grain product, and even
René88DT with a comparable microstructure, increases with application temperature-time severity. While some changes in microstructure and performance were observed, the relative stability and fatigue capability provides an alloy and processing option that provides a significant improvement in durability for extreme conditions.

\section{Conclusions}

- René104 showed a nominal $110^{\circ} \mathrm{C}$ advantage over AsHIP René95 in sustained-peak LCF capability. Evaluated isothermally, René 104 life advantage was $10 \mathrm{X}$ at $704^{\circ} \mathrm{C}$ and $100 \mathrm{X}$ at 760 and $815^{\circ} \mathrm{C}$.

- René104 also showed a nominal 4X nominal life benefit when tested to a simulated mission with temperature cycled out of phase with applied stress.

- Based on tensile response, no evidence of embrittlement was noted for René104 after stressed thermal preexposures. Tensile ductility was unaffected by the temperature-time range evaluated as opposed to reductions measured for As-HIP René95 at these extreme conditions.

- René104 room temperature tensile strength was also unaffected by pre-exposure. The $650^{\circ} \mathrm{C}$ ultimate and yield strength retention was far superior to that of AsHIP René95 over the evaluated range.

- Hardness was confirmed a poor measure of age condition for René104. A slight hardness increase was followed by decay at an extreme $870^{\circ} \mathrm{C}$ condition.

- Thermal exposure above the age temperature coarsens both cooling and aging $\gamma^{\prime}$ of René104. Extreme conditions dissolve age $\gamma^{\prime}$ as cooling $\gamma$ precipitates begins to coalesce.

- Additional grain boundary phases precipitate in a discontinuous manner through $815^{\circ} \mathrm{C}$ and 636 hours. A grain boundary film was formed after extended time at $870^{\circ} \mathrm{C}$.

- René104 showed no evidence of acicular TCP phases over conditions ranging to $870^{\circ} \mathrm{C}$ and 640 hours.

\section{Acknowledgments:}

Authors gratefully acknowledge technical and fiscal support of GE Aircraft Engines and the U.S. Government Naval Air Warfare Center Division, especially Drs. Gil London and Steve Fishman via the Dual Use Science and Technology initiative. Results presented were result of a team effort including representatives from GEAE Materials, Design, Life and Methods. The cooperation of and expertise of Wyman Gordon-PCC were critical to successful completion of this effort. Cameron Begg of the Ohio State University is also recognized for generating FESEM images presented in this document. 


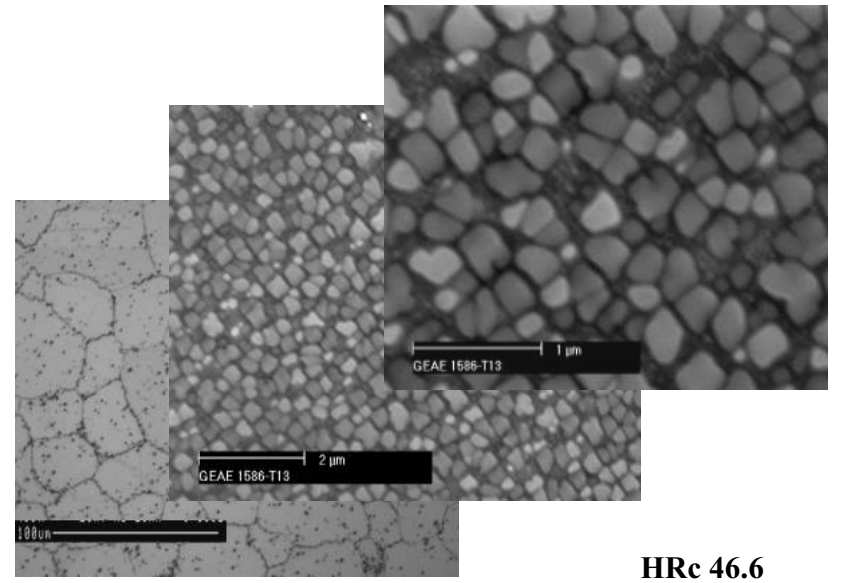

Figure 12 As-heat treated René104 microstructure images provide initial cooling and age $\gamma$ distribution.

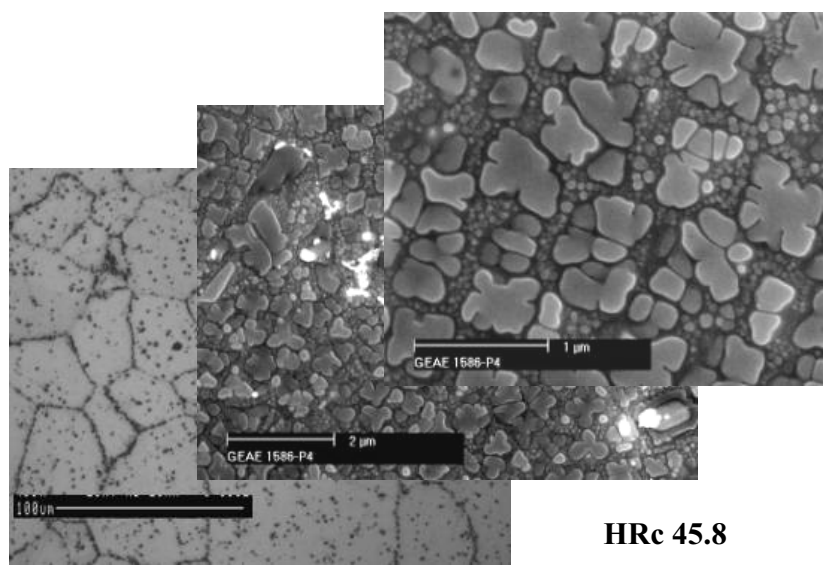

Figure 13 Dual slope cooling rate of the bar used for the $760^{\circ} \mathrm{C} / 25$ hour exposure is indicated by dendritic cooling $\gamma$ of the specimen exposed to $760^{\circ} \mathrm{C} / 25$ hours. Age $\gamma$ precipitates are more easily resolved due to slight coarsening.

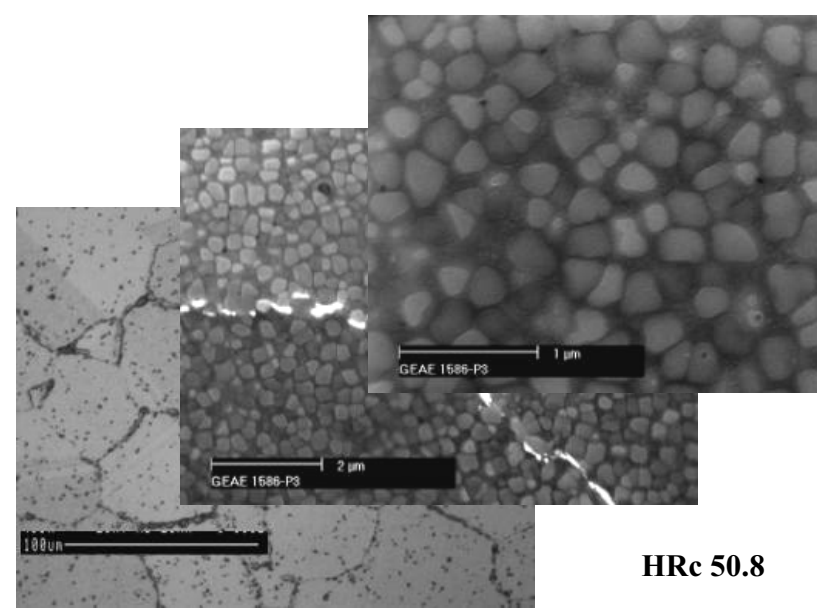

Figure 14 After 599 hours at $760^{\circ} \mathrm{C}$, additional grain boundary precipitation and partial dissolution are evident.

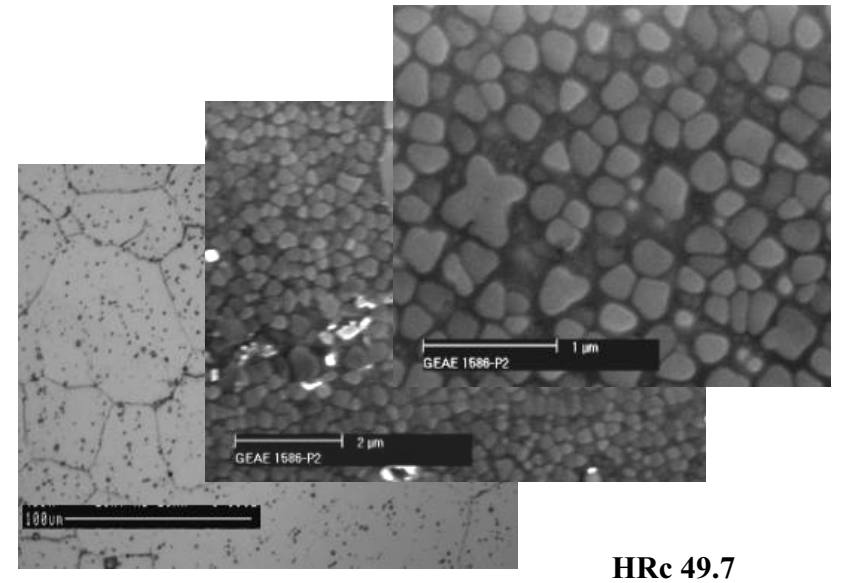

Figure 15 René104 shows grain boundary precipitates and cooling + age $\gamma$ after 25 hours, $815^{\circ} \mathrm{C}$ exposure.

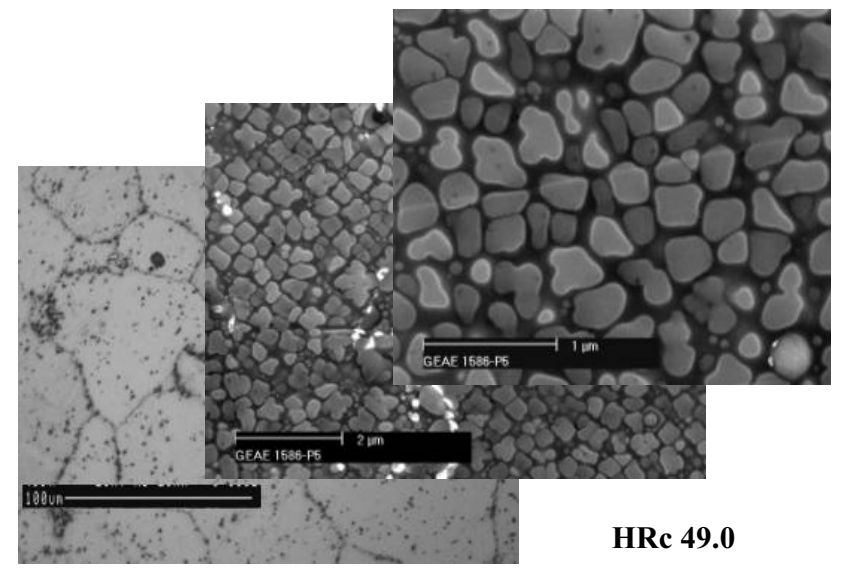

Figure 16 René104 shows grain boundary precipitates and coarsened cooling $\gamma$ and very low fraction age $\gamma$ after 150 hours, $815^{\circ} \mathrm{C}$ exposure. Age $\gamma$ was dissolved by 636 hours at this condition $(48.3 \mathrm{HRc})$.

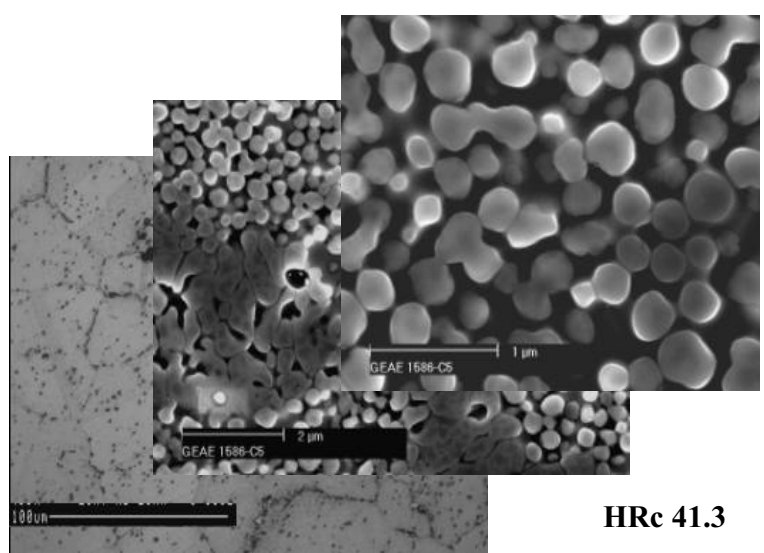

Figure 17 René104 shows extensive grain boundary precipitates plus age + cooling $\gamma$ coarsening after 430 hours, $870^{\circ} \mathrm{C}$ exposure. 


\section{References}

1. Enabling Propulsion Materials Program, Contract NAS326385.

2. T.P. Gabb, J. Gayda, and J. Telesman, "Development of Advanced Powder Metallurgy Disk Alloys in NASAIndustry Programs", Aeromat 2001, Long Beach, CA, June 14, 2001.

3. "Advanced Nickel Alloy Turbine Rotating Components" Naval Air Warfare Center Aircraft Division, Dual Use Science \& Technology Contract N00421-02-3-3011.

4. European Patent Application EP1 195446 A1, "Ni Base Superalloy and It's Use in Gas Turbine Disks, Shafts, and Impellers", D.P. Mourer, K.R. Bain, P.L. Reynolds, J.J. Shirra, T.P. Gabb, 4/10/2000.

5. G.E. Maurer, W. Castledyne, F.A. Schweitzer, and S. Mancuso, "Development of HIP Consolidated P/M Superalloys for Conventional Forging to Gas Turbine Engine Components", Superalloys 1992, pp 645652,Warrendale, PA, TMS, 1992.

6. D.D. Krueger, R.D. Kissinger, and R.G. Menzies, "Development and Introduction of a Damage Tolerant High Temperature Nickel-base Disk Alloy, René88DT", Superalloys 1992, pp 277-296, Warrendale, PA, TMS, 1992.

7. Private communication and proprietary modeling results, Wyman Gordon- Worcester, Mass, 2002.

8. AMS5707, "Nickel Alloy, Corrosion and Heat Resistant, Bars, Forgings, and Rings", UNS \# N07001, Waspaloy.

9. J.F. Barker, E.W. Ross, and J.F. Radavich, Journal of Metals, January 1970.

10. M. Gigliotiti, R. Rohling, J.R.Groh, D.P. Mourer, internal GE Study of Unstressed Thermal Exposure René104, 2001.

11. G.E. Korth and G.L. Trybus, "Tensile Properties and Microstructure of Alloy 718", Superalloys 718, 625, and Various Derivatives, pp. 437-446, TMS Warrendale, PA, 1991.

12. L. Glitsch, internal GEAE documentation, "As-HIP René95 High Temperature Exposure on Microstructure, Creep, and E.T. Tensile Properties", 1989.

13. S.T. Wlodek, M. Kelly, and D.A. Alden, "The Structure of René88DT", Superalloys 1996, pp 129136, Warrendale, PA, TMS, 1996.

14. M.F.X. Gigliotti, R.B. Rohling, E.L. Hall, internal GEGRC documentation, "Long Life Disks, An Interim Report on Exposures Through 25,000 Hours", 11/1999.

15. J.R. Groh, unpublished René'104 Cooling Rate studies.

16. J.R. Groh, internal GEAE documentation of René41 Heat Treat Studies, 1994.

17. S.T. Wlodek, M. Kelly, and D.A. Alden, "The Structure of René88DT", Superalloys 1996, pp.129-136, Warrendale, PA, TMS, 1996. 